\title{
Traditional and new strategies in the primary prevention of eating disorders: a comparative study in Spanish adolescents
}

This article was published in the following Dove Press journal:

International Journal of General Medicine

30 August 2010

Number of times this article has been viewed

\author{
Ignacio Jáuregui Lobera' \\ Pilar León Lozano \\ Patricia Bolaños Ríos ${ }^{3}$ \\ Juan Romero Candau ${ }^{2}$ \\ Gregorio Sánchez del \\ Villar y Lebreros ${ }^{4}$ \\ M Teresa Morales Millán ${ }^{1,5}$ \\ M Teresa Montaña \\ González ${ }^{1,5}$ \\ Lourdes Andrés Martín ${ }^{2}$ \\ Isabela Justo Villalobos ${ }^{2}$ \\ Nuria Vargas Sánchez ${ }^{2}$ \\ 'Área de Nutrición y Bromatología, \\ Universidad Pablo de Olavide; \\ ${ }^{2}$ Colegio Oficial de Farmacéuticos; \\ ${ }^{3}$ Instituto de Ciencias de la Conducta; \\ ${ }^{4}$ Instituto de Enseñanza Secundaria \\ "Murillo"; ${ }^{5}$ Facultad de Farmacia, \\ Universidad de Sevilla, Sevilla, Spain
}

Correspondence: Ignacio Jáuregui Lobera Virgen del Monte,

3I Seville 4I0II Spain

Tel +34954280789

Fax +34954 278167

Email ijl@tcasevilla.com
Background: Research conducted to date into the primary prevention of eating disorders (ED) has mainly considered the provision of information regarding risk factors. Consequently, there is a need to develop new methods that go a step further, promoting a change in attitudes and behavior in the target population.

Objective: This study describes an adaptation of the Girls' Group model to the Spanish context, the main objective being to compare two types of intervention, ie, one based on this model and the other following the traditional approach of providing information. The ultimate aim was to implement a prevention program that reduces the risk factors and boosts the protection factors that have been empirically shown to be related to ED.

Methods: On the basis of previous research on the primary prevention of ED, and taking into account recognized risk and protective factors, the following topics were addressed: nutritional aspects; self-esteem; coping strategies; the ideal image of what is attractive and role of the media; and body image. The total sample (174 girls and 197 boys) was divided into 12 work groups, six for the intervention group (one school) and six for the control group (two schools). School-based input (intervention group) was provided by a pharmacist, a psychologist, a qualified nutritionist/dietician, and specialist support staff (psychologists and/or educators) and teachers of the three schools.

Results: Participation in the intervention group reduced body dissatisfaction ( $\mathrm{F}=13.41$; $P<0.01)$, the drive to thinness $(\mathrm{F}=10.79 ; P<0.01)$, and the influence of the media with respect to the esthetic body shape model ( $\mathrm{F}=13.90 ; P<0.01)$, while self-esteem $(\mathrm{F}=7.34$; $P<0.01)$ and the use of coping strategies $(\mathrm{F}=13.74 ; P<0.01)$ both improved. There was also an improvement in the eating habits of participants, with better outcomes being achieved when intervening with females.

Conclusions: The present study shows that in the primary prevention of eating disorders, better outcomes are achieved by new models which target the attitudes and behavior of adolescents rather than focusing solely on the provision of risk information to raise awareness.

Keywords: coping strategies, adolescence, primary prevention, eating disorders, positive psychology

\section{Introduction}

Traditional prevention programs for eating disorders (ED), which are mainly based on providing information about risk factors, have so far proved largely unsuccessful. ${ }^{1,2}$ Although certain changes in content ${ }^{3}$ have improved these programs, research has yet to demonstrate any clear effects in terms of a change in subjects' knowledge, attitudes, and behavior, especially in the case of children and adolescents. ${ }^{4}$ Therefore, in order to address these aspects, it is necessary to devise programs that include interactive 
components, which implies active participation in workshops rather than the passive receipt of information. ${ }^{5}$

In this context, it has been argued that at the level of primary prevention it is best not to make ED the specific focus of any intervention. ${ }^{6}$ It is also considered that the best place in which to promote the mental health of children and adolescents is the school. Indeed, schools are an ideal place to run prevention programs in that they offer access to the majority of adolescents. ${ }^{7,8}$ A further issue is that parents, alongside teachers, coaches, and other school staff, play a key role in the social environment of young people and, as such, may be included in any interventions. ${ }^{9}$ Finally, it appears that a positive psychology framework, ie, one that focuses on positive human qualities, should replace the traditional approach, with its almost exclusive emphasis on risk factors. ${ }^{10,11}$

Research has shown that multimodal programs (ie, those involving different components and a range of participants) which include skills training for both adolescents and their parents are more effective than those which focus on one group or the other. Indeed, it seems that the best approach is to involve parents, teachers, and adolescents in an attempt to modify both the school and home environments. ${ }^{8}$ However, to date, hardly any prevention programs have focused on eating attitudes and behavior when involving mothers, fathers, sons, and daughters. In fact, very few ED prevention programs have included parents. ${ }^{12}$

An additional factor to consider is that the most positive outcomes seem to be achieved through selective, interactive, and multisession programs. ${ }^{13}$ Recent meta-analyses ${ }^{2,4,13}$ have shown that the greatest effects are obtained through interactive interventions, a constructivist approach (ie, the interaction between the knowledge provided and the active inner reflection of the person receiving the information), a positive psychology framework, the involvement of facilitators with experience in the field of ED, content that promotes cognitive dissonance, multiple sessions, and work with females. However, other authors have noted the lack of studies that actually include all these components. ${ }^{14}$

In light of the above, selective, primary prevention programs (those targeted at a generally healthy population, but with a special risk for a particular disorder) may, if based in schools, provide an opportunity to reduce the current incidence of $\mathrm{ED}$, the prevalence in the community of which has remained largely unchanged since the 1990s. ${ }^{14}$ School-based programs with a focus on risk factors for females, and which include interactive elements, induction of cognitive dissonance, and booster sessions, have been shown to yield significant effects under rigorous methodologic conditions. ${ }^{15-17}$ Similarly, a school-based prevention program, known as the Girls' Group, ${ }^{18}$ has been under development since 2006, the aim being to put into practice the most recent findings mentioned above. The follow-up conducted to date suggests that this program is achieving positive outcomes. ${ }^{14}$

The present study describes an adaptation of the Girls' Group model to the Spanish context, the main aim being to compare two types of intervention, ie, one based on this model and the other following the traditional approach of providing information. The ultimate aim was to implement a prevention program that reduces the risk factors and boosts the protection factors that have been shown empirically to be related to ED.

In order to assess the utility of this intervention we formulated a series of hypotheses, in line with the original work carried out by Scime and Cook-Cottone, ${ }^{14}$ on which the present adaptation is based. These hypotheses were: participation in the intervention group would reduce body dissatisfaction and the drive to thinness; it would reduce the influence of the media with respect to the esthetic body shape model; it would improve self-esteem and the use of coping strategies; it would improve the eating habits of participants; and on the basis of previous research and recommendations, better outcomes would be expected when intervening with females.

\section{Material and methods}

The research design was prospective and observational, with measurement of the outcomes of active intervention (intervention group, one school) and no intervention (control group, two schools).

\section{Participants}

The sample comprised 371 students (corresponding to half the number in each year group considered, chosen at random from the different centers). Of these, 27 were subsequently excluded from the study, either because they failed to complete all the tests or did so inadequately, or because it was not possible to obtain adequate anthropometric data (three students refused to undergo anthropometric assessment). Before starting the interventions, the psychologist attached to each school interviewed the participants in order to ensure that none of them presented (or had a history of) any form of ED. The students belonged to four secondary level year groups and two high-school groups. The total sample, comprising 174 girls and 197 boys, was divided into 12 work groups, six for the intervention group 
(one school) and six for the control group (two schools). School-based input for the intervention group was provided by a pharmacy graduate, a psychology graduate, a qualified nutritionist/dietician, and the teachers and specialist support staff (psychologists and/or educational advisers) of the three schools.

\section{Setting}

The study was conducted between September 2008 and June 2009. The committee for food issues of the Pharmaceutical Society of Seville wrote to state schools in the city, inviting them to take part in a study regarding a prevention program for ED that would be targeted at secondary and high-school students. Nine schools replied to the invitation, of which any that did not offer high-school studies were excluded. Three schools were then chosen randomly from the remainder, because the geographic location of these remaining schools suggested there would be no important sociodemographic differences between them. Permission to conduct the research was given by the schools' governing bodies and the corresponding parents' associations. Following discussion with these bodies, it was left to the individual participant's discretion as to whether the questionnaires would be responded to anonymously or not. In addition to the abovementioned permission, consent was also obtained from all participants and their parents or guardians. Likewise, authorization was given by the ethical committees of the Seville Pharmaceutical Society and the Behavior Research Institute of Seville. Participants received no recompense for taking part in the study.

\section{Measures}

Both the intervention and control groups completed a series of questionnaires before and after the intervention. The first evaluation took place in September 2008, while the second was done in June 2009, one month after the end of the intervention. Data regarding age, gender, weight, and height were also collected in order to calculate body mass index (BMI). In addition, given that the first assessment was conducted at the start of the academic year and the second towards the end of the same year (a time when most students were engaged in their end-of-year exams), we also compared the degree of stress using the Perceived Stress Questionnaire (PSQ) at both assessment points, without finding any significant differences (Table 1).

\section{Eating Disorders Inventory-2}

The Eating Disorders Inventory-2 (EDI-2) $)^{23}$ is a self-report questionnaire with 11 subscales (drive for thinness, bulimia,
Table I Perceived stress at the two assessment points

\begin{tabular}{llllll}
\hline & \multicolumn{2}{l}{ Intervention group } & & \multicolumn{2}{l}{ Control group } \\
\cline { 2 - 3 } \cline { 5 - 6 } & Before & After & & Before & After \\
\hline PSQ-G & $63.89 \pm 9.39$ & $63.56 \pm 7.51$ & & $63.80 \pm 7.92$ & $63.40 \pm 8.49$ \\
PSQ-R & $63.70 \pm 9.75$ & $63.99 \pm 9.88$ & & $65.21 \pm 8.34$ & $65.84 \pm 9.60$ \\
\hline
\end{tabular}

Abbreviations: PSQ-G, Perceived Stress Questionnaire-general form; PSQ-R, Perceived Stress Questionnaire-recent form.

body dissatisfaction, ineffectiveness, perfectionism, interpersonal distrust, interoceptive awareness, maturity fears, asceticism, impulse regulation, and social insecurity). For this study, the body dissatisfaction (BD), bulimia (B), and drive for thinness (DT) scales were administered. The BD subscale measures dissatisfaction with the overall shape and size of those parts of the body most related to eating disorders. The B scale was designed to assess tendencies to think about and to engage in overeating episodes. The DT subscale measures excessive concern with dieting, preoccupation with weight, and fear of weight gain. The EDI-2 has been used to monitor psychologic change during treatment of eating disorders, and the DT subscale has been used as a screening test. ${ }^{24}$ The internal consistency of the test and its subscales ranges between 0.83 and 0.92 in patient samples, and between 0.65 and 0.93 for various nonclinical samples. Test-retest reliability ranges between 0.41 and 0.97 depending on the sample. The Spanish adaption of the EDI-2 was used here.

\section{Self-Esteem Scale}

The Self-Esteem Scale (SES) ${ }^{25}$ comprises 10 items that are scored using a Likert format (from "strongly agree" to "strongly disagree"), ie, the higher the score, the higher the degree of self-esteem. The Spanish version ${ }^{26}$ of the instrument, which was the one used here, shows adequate internal consistency (Cronbach's $\alpha$ coefficient $=0.87$ ), test-retest reliability $(r=0.72)$ and construct validity.

\section{Coping Strategies Inventory}

The Coping Strategies Inventory $(\mathrm{CSI})^{27}$ is a test in which eight primary, four secondary, and two tertiary strategies are explored on the basis of the description of a stressful situation. Individuals respond to 72 items (scored on a fivepoint Likert scale) in which they indicate how often, in the described situation, they did what is expressed by each item. At the end they respond to a further item about the perceived self-efficacy of their coping. The Spanish version ${ }^{28}$ of the CSI shows excellent psychometric properties, with Cronbach's $\alpha$ coefficients between 0.63 and 0.89 . 


\section{Questionnaire of Influences on Body Shape Model}

The version of the Questionnaire of Influences on Body Shape Model (CIMEC and CIMEC-V) ${ }^{29,30}$ used here has 40 items, each of which has three possible responses ("a great deal", "slightly", or "not at all"). The CIMEC and CIMEC-V (for females and males, respectively) explore the following areas of influence: behaviors aimed at weight loss; body-related anxiety; interpersonal influences; influence of ideal body models; family influences; influence of friends; influence of advertising; concerns related to fatness; concerns about being thin; and influence of social models. In the study in which the CIMEC was validated, it showed adequate reliability (Cronbach's $\alpha>0.70$ ), as well as adequate criterion validity in terms of its correlations with the Eating Attitudes Test (EAT).

\section{Perceived Stress Questionnaire}

The $\mathrm{PSQ}^{31}$ was designed to measure stress, and consists of 30 items that differentially measure the general and recent forms of perceived stress. The validation study for the Spanish population ${ }^{32}$ showed excellent psychometric properties (internal consistency was 0.90 for the General and 0.87 for the Recent PSQ), and the scale has shown good predictive value in research on stress-related diseases. ${ }^{31,32}$

\section{Nutritional intake}

All participants were instructed by a nutritionist on how to complete a three-day food record (inclusive of beverages) covering two week days and one weekend day. Written and verbal guidelines were provided for the estimation of food portions. As part of the instructional session, and in order to check their understanding, participants were asked to describe the portions used and the food preparation details for a minimum of two prior meals. All participants were encouraged to depict typical food consumption. A research nutritionist reviewed the completed food records for clarification of portions and food preparation. Nutrient intakes were calculated from the three-day food records by using the calculation program of the Center for Advanced Studies in Nutrition and Dietetics of the University of Barcelona. ${ }^{33}$

\section{Body mass index}

Students were weighed and measured (without shoes) using calibrated electronic instruments, and BMI scores $\left(\mathrm{kg} / \mathrm{m}^{2}\right)$ were then calculated.

\section{Intervention and procedure}

On the basis of previous research that has indicated the need for preventive intervention to take into account recognized risk and protective factors, ${ }^{19,20}$ and given the recent model of Scime and Cook-Cottone, ${ }^{14}$ we chose to address the following topics: nutritional aspects (degree to which eating habits follow the Mediterranean diet, according to the recommendations of the Spanish Society for Community Nutrition, ${ }^{21,22}$ for the age groups considered); self-esteem; coping strategies; ideal image of what is attractive and the role of the media; and body image. The procedure used was interactive and geared toward the construction of meanings and action. The study groups were organized as follows. The intervention group was formed by subgroups of 31 students. Each of these subgroups took part in two training sessions, one theoretical and one practical (interactive). These sessions took a positive psychology approach without focusing particularly on risk factors, the emphasis being placed on promoting psychologic and physical health in regard to each of the work topics. Each group of students received a total of 10 sessions divided equally into five modules covering the following topics: nutritional aspects, self-esteem, coping strategies, the ideal body shape model, role of the media, and body image. In addition to the sessions with students, two information sessions were run for parents and teachers. In the case of the control group, the students (again in groups of 31) took part in information sessions about eating disorders that followed the traditional approach, ie, the focus was basically on risk factors. All sessions, for both groups, were run by the same professionals.

In order to achieve a student-centered and interactive format, the intervention sessions were designed with the help of digital tools, and also included a set of related activities, both individual- and group-based. The presentations, designed in a multimedia format, included visual effects, photographs, video clips, animated graphics and games, all with the aim of making them appealing to students. All sessions (both the first theoretic one and the second practical workshop) in each module lasted 90 minutes and were run during the normal school day. The initial timetable was agreed with the corresponding teachers, so as not to affect the everyday class schedule. The sessions took place weekly and, in order to balance the groups, were given in a different order for each group. The flowchart shows the organization of the study (see Figure 1).

\section{Statistical analysis}

In order to identify any possible differences between the groups prior to the intervention (pretest differences), a series 


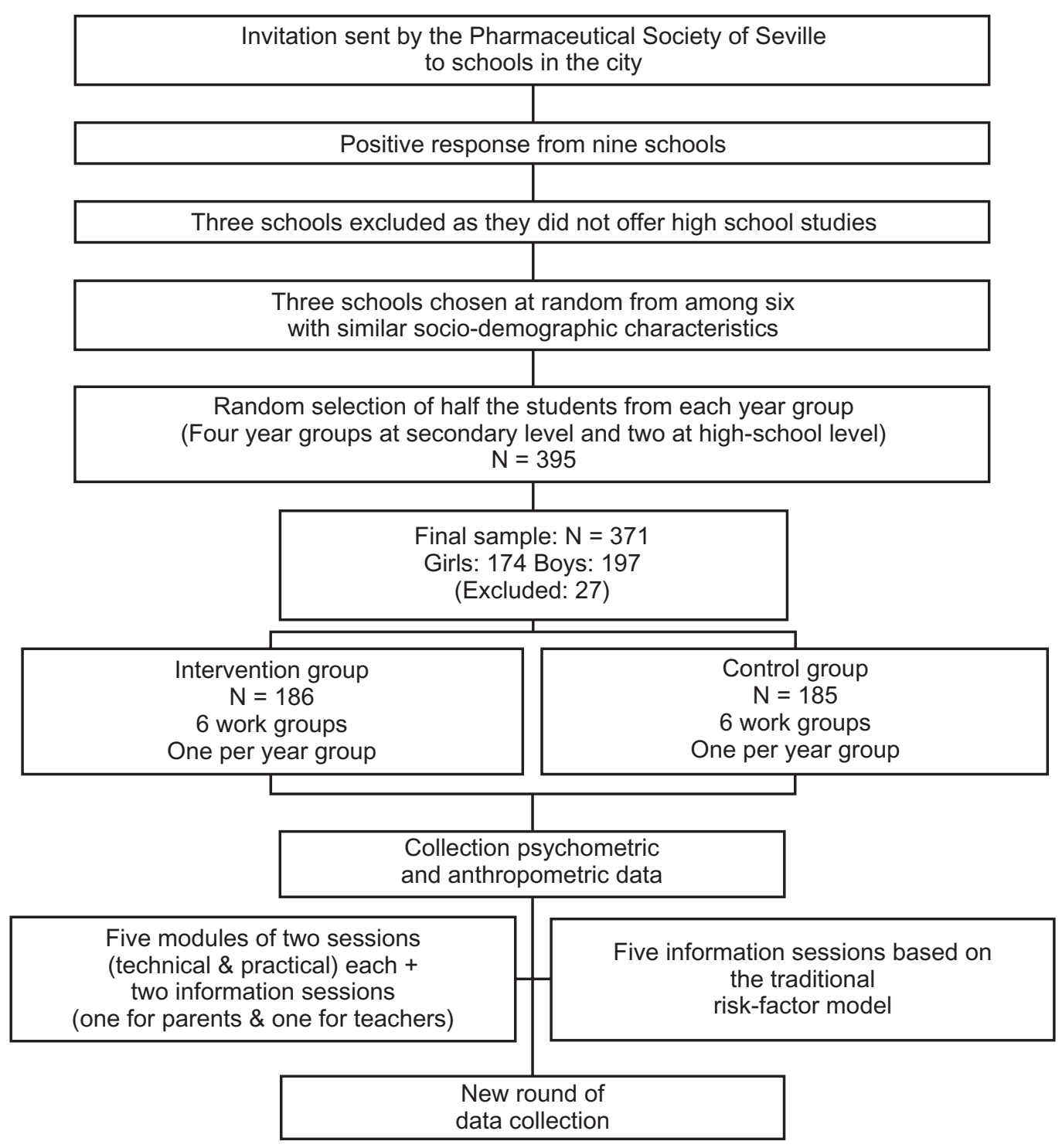

Figure I Organization of the study.

of one-way analyses of variance (ANOVAs) was performed for continuous variables, along with Chi-squared tests for categoric variables. Pre- and postintervention differences in both groups were analyzed by means of a multivariate analysis of variance (MANOVA), which was also used to evaluate any differences between boys and girls in the intervention group. The effect size in the MANOVA and the ANOVA was determined by the (eta $\pm \eta_{\text {partial }}^{2}$ ) coefficient, following the criteria of Cohen ( small $=0.01$, medium $=0.06$, and large $=0.14) \cdot{ }^{34}$ All statistical analyses were performed using the SPSS v 16.

\section{Results}

Demographic characteristics of the participants are summarized in Table 2. The preintervention analysis of the two groups revealed no significant differences for the variables considered, ie, gender, age, BMI, body fat percentage, fat mass percentage, body water percentage, CIMEC, PSQ, CSI, SES, EDI-2, calorie content of diets, proteins, carbohydrates, lipids, saturated fatty acids (SFA), monounsaturated fatty acids (MUFA), polyunsaturated fatty acids (PUFA), fiber, cholesterol, vitamins B6, B9, B12, C, D, E, and A, and the minerals analyzed ( $\mathrm{Ca}, \mathrm{Fe}, \mathrm{Zn}$, and $\mathrm{Na})$.

\section{Hypothesis I}

"Participation in the intervention group would reduce body dissatisfaction and the drive to thinness, both of which would remain similar in the control group."

Participation in the intervention group was associated with a statistically significant reduction in both the drive 
Table 2 Characteristics of the study participants

\begin{tabular}{|c|c|c|c|c|c|c|c|c|}
\hline \multirow[t]{2}{*}{ Variable } & \multicolumn{4}{|c|}{ Intervention group $(n=186)$} & \multicolumn{4}{|c|}{ Control group $(n=185)$} \\
\hline & $M$ & SD & $\mathbf{n}$ & $\%$ & $\bar{M}$ & SD & $\mathbf{n}$ & $\%$ \\
\hline Age & 14.72 & 1.95 & & & 14.99 & 1.80 & & \\
\hline \multicolumn{9}{|l|}{ Sex } \\
\hline Male & & & 101 & 54.30 & & & 99 & 53.51 \\
\hline Female & & & 85 & 45.70 & & & 86 & 46.49 \\
\hline \multicolumn{9}{|c|}{ Educational level } \\
\hline Secondary & & & 123 & 66.12 & & & 115 & 62.16 \\
\hline \multicolumn{9}{|c|}{ Four-year groups } \\
\hline High school & & & 63 & 33.88 & & & 70 & 37.84 \\
\hline BMI & & & 21.29 & 3.64 & & & 21.55 & 3.48 \\
\hline
\end{tabular}

Abbreviations: BMI, body mass index; SD, standard deviation.

to thinness, ie, the DT subscale of the EDI-2 ( $\mathrm{F}=10.79$, $\left.P<0.01, \eta_{\text {partial }}^{2}=0.04\right)$ and body dissatisfaction, ie, the BD subscale of the EDI-2 ( $\left.\mathrm{F}=13.41, P<0.01, \eta_{\text {partial }}^{2}=0.05\right)$. There were no significant changes in the control group.

\section{Hypothesis 2}

"Participation in the intervention group would reduce the influence of the media with respect to the esthetic body shape model, which would remain similar in the control group."

Taking into account the subscales of the CIMEC and CIMEC-V, there was a significant reduction in the influence of ideal models $\left(\mathrm{F}=8.90, P<0.01, \eta_{\text {partial }}^{2}=0.03\right)$, family influences $\left(\mathrm{F}=24.44, P<0.01, \eta_{\text {partial }}^{2}=0.08\right)$, interpersonal influences $\left(\mathrm{F}=9.16, P<0.01, \eta_{\text {partial }}^{2}=0.03\right)$, the influence of advertising $\left(\mathrm{F}=13.90, P<0.01, \eta_{\text {partial }}^{2}=0.05\right)$, and the total score on the questionnaire $\left(\mathrm{F}=7.47, P<0.05, \eta_{\text {partial }}^{2}=0.03\right)$. On the remaining subscales (concerns about being thin, influence of social models, influence of friends, behaviors aimed at weight loss, body-related anxiety, and concerns about being fat), scores were lower after the intervention but without reaching statistical significance. In the control group, a significant difference was only observed for interpersonal influences $\left(\mathrm{F}=8.14, P<0.01, \eta_{\text {partial }}^{2}=0.03\right)$.

\section{Hypothesis 3}

"Participation in the intervention group would improve selfesteem and the use of coping strategies, which would remain similar in the control group."

SES improved after the intervention $(\mathrm{F}=7.34, P<0.01$, $\left.\eta_{\text {partial }}^{2}=0.03\right)$, but showed no change in the control group. As regards the use of coping strategies (measured by CSI) the intervention group showed a reduction in self-criticism $\left(\mathrm{F}=18.37, P<0.01, \eta_{\text {partial }}^{2}=0.09\right)$ and a considerable improvement in perceived self-efficacy $(\mathrm{F}=13.74, P<0.01$, $\left.\eta_{\text {partial }}^{2}=0.05\right)$. The remaining subscales also showed an improvement but without reaching statistical significance. Postintervention scores in the control group showed no significant positive changes, and the use of avoidance strategies actually increased $\left(\mathrm{F}=9.47, P<0.01, \eta_{\text {partial }}^{2}=0.04\right)$.

\section{Hypothesis 4}

"The prevention program would lead to improved eating habits in the intervention group, whereas these habits would remain unchanged in the control group."

There was a considerable postintervention improvement in the intervention group in terms of the intake of MUFA $\left(\mathrm{F}=7.60, P<0.01, \eta_{\text {partial }}^{2}=0.03\right)$, PUFA $(\mathrm{F}=7.56$, $\left.P<0.01, \eta_{\text {partial }}^{2}=0.03\right)$, vitamin $\mathrm{B}_{12}(\mathrm{~F}=30.41, P<0.01$, $\left.\eta_{\text {partial }}^{2}=0.10\right)$, vitamin $\mathrm{C}\left(\mathrm{F}=5,025, P<0.01, \eta_{\text {partial }}^{2}=\right.$ $0.03)$, vitamin $\mathrm{E}\left(\mathrm{F}=11.32, P<0.01, \eta_{\text {partial }}^{2}=0.05\right)$, and vitamin $\mathrm{A}\left(\mathrm{F}=3.92, P<0.05, \eta_{\text {partial }}^{2}=0.01\right)$. In the control group there were no significant differences in the intake of either macro- or micronutrients.

\section{Hypothesis 5}

"On the basis of previous research and recommendations, better outcomes would be expected when intervening with females."

Tables 3 and 4 show the gender-based differences in preand postintervention scores for the intervention and control groups, respectively.

\section{Discussion}

Using an adaptation of the Girls' Group mode ${ }^{18}$ to the Spanish context, the aim of the present study was to evaluate the efficacy of a prevention program designed to reduce the risk factors and boost the protection factors that have been empirically shown to be related to ED. The choice of this model enables the most relevant research findings to date ${ }^{18,35}$ to be incorporated into the prevention program. As in the study by 
Table 3 Pre- and postintervention differences by gender

\begin{tabular}{|c|c|c|c|c|}
\hline & \multicolumn{4}{|c|}{ Intervention group I } \\
\hline & \multicolumn{2}{|l|}{ Girls } & \multicolumn{2}{|l|}{ Boys } \\
\hline & Pre & Post & Pre & Post \\
\hline \multicolumn{5}{|c|}{ EDI-2 subscales } \\
\hline DT & $3.95 \pm 2.67$ & $2.01 \pm 1.65^{* *}$ & $2.35 \pm 2.08$ & $1.92 \pm 1.44$ \\
\hline $\mathrm{BD}$ & $5.92 \pm 4.02$ & $3.32 \pm 3.25 * *$ & $4.29 \pm 3.26$ & $2.67 \pm 2.58^{*}$ \\
\hline \multicolumn{5}{|c|}{ CIMEC and subscales } \\
\hline IIM & $1.32 \pm 1.06$ & $0.92 \pm 0.84 *$ & $1.20 \pm 0.87$ & $0.95 \pm 0.67$ \\
\hline $\mathrm{FI}$ & $1.43 \pm 1.01$ & $0.89 \pm 0.67^{* *}$ & $1.04 \pm 0.88$ & $0.58 \pm 0.47^{* *}$ \\
\hline ॥ & $3.25 \pm 2.07$ & $2.00 \pm 1.52 * *$ & $3.16 \pm 2.42$ & $2.67 \pm 2.45$ \\
\hline IA & $2.23 \pm 2.04$ & $1.13 \pm 0.98 * *$ & $1.27 \pm 1.18$ & $0.58 \pm 0.49 * *$ \\
\hline CIMEC & $17.22 \pm 8.30$ & $|I .4| \pm 6.27^{* *}$ & $|5.22 \pm 8.2|$ & $13.98 \pm 7.29$ \\
\hline \multicolumn{5}{|c|}{ Self-esteem scale } \\
\hline & $30.77 \pm 4.89$ & $33.19 \pm 4.95^{* *}$ & $31.04 \pm 5.10$ & $31.91 \pm 5.04$ \\
\hline \multicolumn{5}{|c|}{ CSI subscales } \\
\hline SC & $5.34 \pm 4.14$ & $3.11 \pm 2.80 * *$ & $7.45 \pm 5.33$ & $4.47 \pm 2.83^{* *}$ \\
\hline WT & $13.14 \pm 5.29$ & $13.03 \pm 4.84$ & $11.42 \pm 4.93$ & $9.64 \pm 4.78^{*}$ \\
\hline sW & $5.77 \pm 4.74$ & $4.17 \pm 3.24 *$ & $6.26 \pm 4.27$ & $7.04 \pm 4.54$ \\
\hline $\mathrm{PE}$ & $2.80 \pm 1.30$ & $3.30 \pm 0.66 * *$ & $2.51 \pm 1.33$ & $3.01 \pm 0.55^{*}$ \\
\hline \multicolumn{5}{|l|}{ Intake } \\
\hline Lipids & $83.92 \pm 34.50$ & $95.28 \pm 30.26 *$ & $91.98 \pm 33.16$ & $92.57 \pm 41.21$ \\
\hline MUFA & $37.10 \pm 16.19$ & $44.92 \pm 14.92 * *$ & $42.33 \pm 16.80$ & $45.73 \pm 22.02$ \\
\hline PUFA & $8.20 \pm 4.53$ & $10.85 \pm 4.36 * *$ & $9.58 \pm 4.97$ & $9.10 \pm 4.27$ \\
\hline Vitamin $B_{12}$ & $3.46 \pm 2.61$ & $6.14 \pm 5.09 * *$ & $3.45 \pm 2.00$ & $5.14 \pm 2.35$ \\
\hline Vitamin C & $85.50 \pm 60.70$ & $117.18 \pm 82.90^{* *}$ & $91.39 \pm 67.05$ & $90.19 \pm 67.69$ \\
\hline Vitamin E & $5.34 \pm 2.71$ & $7.61 \pm 3.02 * *$ & $5.95 \pm 3.64$ & $6.34 \pm 3.88$ \\
\hline Vitamin A & $650.25 \pm 345.54$ & $858.70 \pm 617.73 *$ & $650.61 \pm 362.36$ & $672.01 \pm 504.48$ \\
\hline
\end{tabular}

Notes: $* P<0.05 ; * * P<0.01$.

Abbreviations: DT, drive for thinness; BD, body dissatisfaction; IIM, influence of ideal models; Fl, family influences; II, interpersonal influences; IA, influence of advertising; SC, self-criticism; WT, wishful thinking; SW, social withdrawal; PE, perceived efficacy; MUFA, monounsaturated fatty acids; PUFA, polyunsaturated fatty acids; EDI-2, Eating Disorders Inventory-2, CIMEC, Questionnaire of Influences on Body Shape model; CSI, Coping Strategies Inventory.

Scime and Cook-Cottone, ${ }^{14}$ the intervention was shown to improve both body dissatisfaction and the drive to thinness, both of which are strongly associated with eating disorders. However, in contrast with the study by these authors, ${ }^{14}$ the present research did not observe significant changes in bulimic behavior. At all events, the low pre- and postintervention scores on this subscale, similar to those reported by the aforementioned authors, suggest that this behavior is of limited relevance in the sample analyzed. Furthermore, many girls with negative attitudes towards their body, and who begin to diet, do not report regular episodes of binging. ${ }^{36}$

A partial reduction in the influence of the esthetic body shape model was observed after the intervention. The developmental stage considered here is associated with a sharp rise in dysfunctional eating, ${ }^{37}$ especially among girls. ${ }^{38}$ However, the internalization of the body shape model is not, as is often argued, based exclusively on the influence of the media. Peer group, family, magazines, and articles are all channels through which an ideal standard of what is attractive can be transmitted. ${ }^{39-43}$ Family attitudes toward food and a concern with weight and body appearance are also considered to be risk factors for the onset of dysfunctional eating patterns. ${ }^{44-46}$ Indeed, the family has come to be considered as an element of key psychosocial influence as regards the vulnerability to such problems. ${ }^{47-49}$ With respect to these risk factors, the present study reports a reduction in the influence of ideal models, of interpersonal influences and advertising, as well as a lower total score on the questionnaire used to assess these influences. In other areas of influence (concerns about being thin, influence of social models, influence of friends, behaviors aimed at weight loss, body-related anxiety, and concerns about being fat), scores were also lower after the intervention, but without reaching statistical significance. If these findings are compared with those obtained from the subscales of the EDI-2 it can be concluded that, over the study period, the preventive program managed to reduce the effect of certain core aspects of eating disorders. However, the influence of other areas of social pressure to be thin remained unchanged in the individuals' perception.

Given that dysfunctional eating patterns depend on the balance between risk and protective factors, self-esteem and 
Table 4 Pre- and postdifferences by gender in the control group

\begin{tabular}{|c|c|c|c|c|}
\hline & \multicolumn{4}{|c|}{ Control group I } \\
\hline & \multicolumn{2}{|l|}{ Girls } & \multicolumn{2}{|l|}{ Boys } \\
\hline & Pre & Post & Pre & Post \\
\hline \multicolumn{5}{|c|}{ EDI-2 subscales } \\
\hline DT & $4.38 \pm 3.32$ & $3.88 \pm 2.97$ & $2.38 \pm 2.31$ & $2.4 \mathrm{I} \pm 1.77$ \\
\hline $\mathrm{BD}$ & $5.38 \pm 3.99$ & $5.02 \pm 3.25$ & $4.02 \pm 3.12$ & $4.10 \pm 2.88$ \\
\hline \multicolumn{5}{|c|}{ CIMEC and subscales } \\
\hline IIM & $1.19 \pm 1.03$ & $1.00 \pm 0.97$ & $1.12 \pm 0.91$ & $1.00 \pm 0.84$ \\
\hline $\mathrm{FI}$ & $1.57 \pm 1.05$ & $1.24 \pm 0.93$ & $1.08 \pm 0.87$ & $0.97 \pm 0.89$ \\
\hline II & $4.21 \pm 2.97$ & $3.21 \pm 2.03^{*}$ & $2.84 \pm 1.75$ & $2.57 \pm 1.97$ \\
\hline IA & $2.28 \pm 1.12$ & $2.19 \pm 0.78$ & $2.29 \pm 1.74$ & $2.17 \pm 1.60$ \\
\hline CIMEC & $17.47 \pm 9.20$ & $17.07 \pm 6.89$ & $14.37 \pm 8.05$ & $13.65 \pm 7.08$ \\
\hline \multicolumn{5}{|c|}{ Self-esteem scale } \\
\hline & $31.20 \pm 4.23$ & $31.07 \pm 4.57$ & $31.92 \pm 4.89$ & $32.02 \pm 5.12$ \\
\hline \multicolumn{5}{|c|}{ CSI subscales } \\
\hline SC & $5.46 \pm 4.02$ & $4.98 \pm 3.12$ & $6.43 \pm 5.38$ & $6.44 \pm 5.39$ \\
\hline WT & $|3.42 \pm 4.7|$ & $13.9 \mid \pm 4.98$ & $12.76 \pm 5.19$ & $11.46 \pm 5.11$ \\
\hline sW & $5.58 \pm 4.53$ & $5.33 \pm 4.02$ & $5.5 \mathrm{I} \pm 4.44$ & $5.42 \pm 4.23$ \\
\hline PE & $2.51 \pm 1.31$ & $2.62 \pm 1.22$ & $2.33 \pm 1.38$ & $2.38 \pm 1.42$ \\
\hline \multicolumn{5}{|l|}{ Intake } \\
\hline Lipids & $93.06 \pm 38.82$ & $94.18 \pm 36.27$ & $96.03 \pm 29.29$ & $97.43 \pm 28.52$ \\
\hline MUFA & $36.45 \pm 17.34$ & $36.98 \pm 15.76$ & $43.75 \pm 14.58$ & $44.16 \pm 14.85$ \\
\hline PUFA & $8.91 \pm 4.59$ & $9.11 \pm 4.45$ & $11.29 \pm 6.16$ & $1 \mathrm{I} .00 \pm 4.42$ \\
\hline Vitamin $B_{12}$ & $3.61 \pm 3.06$ & $3.36 \pm 3.13$ & $4.47 \pm 2.35$ & $4.30 \pm 3.30$ \\
\hline Vitamin C & $83.23 \pm 64.12$ & $93.34 \pm 81.08 *$ & $97.34 \pm 67.05$ & $99.39 \pm 65.69$ \\
\hline Vitamin E & $5.61 \pm 2.79$ & $5.92 \pm 3.13$ & $6.85 \pm 3.95$ & $6.71 \pm 3.50$ \\
\hline Vitamin A & $648.89 \pm 348.98$ & $647.96 \pm 366.76^{*}$ & $642.61 \pm 361.09$ & $648.13 \pm 443.57$ \\
\hline
\end{tabular}

Note: $* P<0.05$.

Abbreviations: DT, drive for thinness; BD, body dissatisfaction; IIM, influence of ideal models; FI, family influences; II, interpersonal influences; IA: influence of advertising, SC, self-criticism; WT, wishful thinking; SW, social withdrawal; PE, perceived efficacy; MUFA, monounsaturated fatty acids; PUFA, polyunsaturated fatty acids; EDI-2, Eating Disorders Inventory-2, CIMEC, Questionnaire of Influences on Body Shape model; CSI, Coping Strategies Inventory.

the adequate use of coping strategies are key elements in terms of protection, ones which preventive interventions must seek to foster. ${ }^{50,51}$ In this regard, the current prevention program improved self-esteem in the intervention group, a change that was accompanied by a reduction in self-criticism and better perceived self-efficacy among participants. This contrasts with what was observed in the control group, who made greater use of avoidance strategies, which are regarded as ultimately unhelpful. This combination of improved self-esteem, reduced self-criticism, and a greater sense of perceived self-efficacy leads in general to stronger feelings of self-worth, which is of fundamental importance in social interactions. ${ }^{52} \mathrm{As}$ pointed out by various authors, an improvement in one of these levels may protect against social pressure to lose weight and, consequently, act as a protective factor with regard to the development of eating disorders. . $^{14,53}$

The next hypothesis, which was directly related to the eating habits of participants, was widely supported by the results, especially as regards food quality. After the intervention, the intervention group showed a considerable improvement in intake of MUFA, PUFA, vitamin $B_{12}$, vitamin C, vitamin E, and vitamin A. Indeed, some of the participants reached Recommended Daily Intake values close to the established guidelines for adolescents, while others achieved adequate levels. The initial assessment of food intake showed important deficits in certain nutrients when compared with the levels recommended by the Spanish Society for Community Nutrition $^{21,22}$ for the age groups in question. This finding is consistent with previous research in our context. ${ }^{54}$ The intervention produced a partial improvement in this regard.

The recommendation of recent studies and metaanalyses ${ }^{2,4,13-18}$ that prevention programs should be particularly targeted at females is supported by the present results. Indeed, with the intervention proposed here, the overall benefits were clearly much greater for girls.

The present study does have a number of limitations, first and foremost the absence of any follow-up. Therefore, future studies need to analyze the extent to which the positive outcomes obtained with this intervention are maintained in the medium and long term. Another issue is that the 
recruitment procedure, based on replies to an invitation to participate, meant that the samples had to be chosen on the basis of similar sociodemographic characteristics. It is therefore necessary to analyze whether a choice of groups with different sociodemographic characteristics would have produced differences in the preintervention results of the experimental and control groups. Thirdly, future studies should run the prevention program with girls alone, or, in the event that boys are included, adapt the content of the intervention so as to take into account the possibility of differential gender effects on the risk of dysfunctional eating patterns. Finally, further research is required into the fact that an intervention designed to promote healthy eating and promote general psychologic wellbeing (psychoeducation), but without including pathologic aspects related to eating disorders, leads to better outcomes than those achieved through traditional primary prevention approaches to these (and other) disorders in these age groups.

Despite these limitations the present findings support the idea that better outcomes are achieved through new models of primary prevention, which aim to change attitudes and behavior rather than simply raise awareness through the provision of risk information.

\section{Disclosure}

The authors state that there are no conflicts of interest in this work. This research received no specific grant from any funding agency in the public, commercial, or nonprofit sectors.

\section{References}

1. Littleton HL, Ollendick T. Negative body image and disordered eating behavior in children and adolescents: What places youth at risk and how can these problems be prevented? Clin Child Fam Psychol Rev. 2003;6:51-66

2. Stice E, Shaw H, Marti CN. A meta-analytic review of eating disorder prevention programs: Encouraging findings. Annu Rev Clin Psychol. 2007;3:233-257.

3. Baranowski MJ, Hetherington MM. Testing the efficacy of an eating disorder prevention program. Int J Eat Disord. 2001;29:119-124.

4. Fingeret MC, Warren CS, Cepeda-Benito A, Gleaves DH. Eating disorder prevention research: A meta-analysis. Eat Disord. 2006;14: 191-213.

5. Dalle Grave R, de Luca L, Campello G. Middle school primary prevention program for eating disorders: A controlled study with a twelve-month follow-up. Eat Disord. 2001;9:327-337.

6. Borresen R, Rosenvinge JH. Body dissatisfaction and dieting in 4,952 Norwegian children aged 11-15 years: Less evidence for gender and age differences. Eat Weight Disord. 2003;8:238-241.

7. Seif El-Din A. Prevention and intervention in school settings. In: Remschmidt H, Belfer ML, Goodyer I, editors. Facilitating Pathways. New York, NY: Springer; 2004.

8. Stewart A. Experiencias recogidas en un programa escolar de prevención de los trastornos alimentarios. In: Vandereycken W, Noordenbos G, editors. La Prevención de los Trastornos Alimentarios: Un Enfoque Multidisciplinario. Barcelona, Spain: Granica; 2000.
9. Austin S. Prevention research in eating disorders: Theory and new directions. Psychol Med. 2000;30:1249-1262.

10. Seligman MEP, Csikszentmihalyi M. Positive psychology: An introduction. Am Psychol. 2000;55:5-14.

11. Steck EL, Abrams LM, Phelps L. Positive psychology in the prevention of eating disorders. Psychol Sch. 2004;41:111-117.

12. Graber JA, Brooks-Gunn J, Warren MP. The vulnerable transition: Puberty and the development of eating pathology and negative mood. Womens Health Issues. 1999;9:107-114.

13. Stice E, Shaw H. Eating disorder prevention programs: A meta-analysis review. Psychol Bull. 2004;130:206-227.

14. Scime M, Cook-Cottone C. Primary prevention of eating disorders: A constructivist integration of mind and body strategies. Int $J$ Eat Disord. 2008;41:134-142.

15. Berger U, Joseph A, Sowa M, Strauss B. The Barbie-Matrix: Effectiveness of a school-based German program for the primary prevention of anorexia nervosa developed for girls up to the age of 12. Psychother Psychosom Med Psychol. 2007;57:248-255.

16. Berger U, Sowa M, Bormann B, Brix C, Strauss B. Primary prevention of eating disorders: Characteristics of effective programmes and how to bring them to broader dissemination. Eur Eat Disord Rev. 2008;16:173-183.

17. Berger U, Ziegler P, Strauss B. Barbie goes PriMa: Formative evaluation of a school-based program for the primary prevention of anorexia nervosa developed for girls up to the age of 12. Z Psychosom Med Psychother. 2008;54:32-45.

18. Cook-Cottone C, Kane L. The Satsanga Center for the prevention and treatment of eating disorders. University at Buffalo (SUNY). Available from: http://www.gse.buffalo/cap/satsanga. Accessed Nov 30, 2006.

19. Phelps L, Dempsey M, Sapia J, Nelson L. The efficacy of a school based eating disorder prevention program: Building physical self-esteem and competencies. In: Piran N, Levine MP, Steiner-Adair C, editors. Preventing Eating Disorders: A Handbook of Interventions and Special Challenges. New York, NY: Taylor and Francis; 1999.

20. Stice E. Risk and maintenance factors for eating pathology: A metaanalytic review. Psychol Bull. 2002;128:825-848.

21. Sociedad Española de Nutrición Comunitaria. Guía de la Alimentación Saludable. Barcelona, Spain: Sociedad Española de Nutrición Comunitaria; 2004.

22. Sociedad Española de Nutrición Comunitaria. Guías Alimentarias para la Población Española. Madrid, Spain: Sociedad Española de Nutrición Comunitaria; 2001.

23. Garner DM. Inventario de Trastornos de la Conducta Alimentaria-2. Madrid, Spain: Tea Ediciones; 1998.

24. Mitchell JE, Pyle RL, Eckert ED, Hatsukami D, Pomeroy C, Zimmerman R. A comparison study of antidepressants and structured intensive group psychotherapy in the treatment of bulimia nervosa. Arch Gen Psychiatry. 1990;47:149-157.

25. Rosenberg M. Society and the Adolescent Self-image. Princeton, NJ: Princeton University Press; 1965.

26. Vázquez AJ, Jiménez R, Vázquez-Morejón R. Escala de autoestima de Rosenberg: Fiabilidad y validez en población clínica española. Apuntes de Psicología. 2004;22:247-255.

27. Tobin DL, Holroyd KA, Reynolds RV, Kigal JK. The hierarchical factor structure of the Coping Strategies Inventory. Cognit Ther Res. 1989;13:343-361.

28. Cano FJ, Rodríguez L, García J. Adaptación española del Inventario de Estrategias de Afrontamiento. Actas Esp Psiquiatri. 2007;35:29-39.

29. Toro J, Salamero M, Martínez E. Assessment of sociocultural influences on the aesthetic body shape model in anorexia nervosa. Acta Psychiatr Scand. 1994;89:147-151.

30. Toro J, Castro J, Gila A, Pombo C. Assessment of sociocultural influences on the body shape model in adolescent males with anorexia nervosa. Eur Eat Disord Rev. 2005;13:351-359.

31. Levenstein S, Prantera V, Varvo V, et al. Development of the Perceived Stress Questionnaire: A new tool for psychosomatic research. J Psychosom Res. 1993;37:19-32. 
32. Sanz-Carrillo C, García-Campayo J, Rubio A, Santed MA, Montoro M. Validation of the Spanish version of the Perceived Stress Questionnaire. J Psychosom Res. 2002;52:167-172.

33. Centre d'Ensenyament Superior de Nutrició y Dietètica. Tablas de Composición de Alimentos. Madrid, Spain: McGraw-Hill/Interamericana; 2003.

34. Cohen J. Statistical Power Analysis for the Behavioral Sciences. Hillsdale, NJ: Erlbaum; 1988.

35. Scime M, Cook-Cottone C, Kane L, Watson T. Group prevention of eating disorders with fifth-grade females: Impact on body dissatisfaction, drive for thinness, and media influence. Eat Disord. 2006;14:143-155

36. Jáuregui I, Pérez-Lancho C, Gómez-Capitán MJ, Durán E, Garrido O. Psychometric properties of the Spanish version of the Eating Behaviors and Body Image Test for preadolescents girls (EBBIT). Eat Weight Disord. 2009;14:e22-e28.

37. Crisp AH. The psychopathology of anorexia nervosa: Getting the "heat" out of the system. In: Stunkard AJ, Stellar E, editors. Eating and its Disorders. New York, NY: Raven; 1984.

38. Ackard D, Peterson C. Association between puberty and disordered eating, body image, and other psychological variables. Int J Eat Disord. 2001;29:187-194.

39. Huon $\mathrm{G}$, Walter $\mathrm{G}$. Initiation of dieting among adolescent females. Int $J$ Eat Disord. 2001;28:226-230.

40. Stice E, Maxfield J, Wells T. Adverse effects of social pressure to be thin on young women: An experimental investigation of the effects of "fat talk". Int J Eat Disord. 2003;34:108-117.

41. Toro J, Cervera M, Pérez P. Body shape, publicity and anorexia nervosa. Soc Psychiatry Psychiatr Epidemiol. 1988;23:132-136.

42. Utter J, Neumark-Sztainer D, Wall M, Story M. Reading magazine articles about dieting and associated weight control behaviors among adolescents. J Adolesc Health. 2003;32:78-82.
43. Martínez-González MA, Gual P, Lahortiga F, Alonso Y, Irala-Estévez J, Cervera S. Parental factors, mass media influences, and the onset of eating disorders in a prospective population-based cohort. Pediatrics. 2003;111:315-320.

44. Polivy J, Herman CP. Causes of eating disorders. Annu Rev Psychol. 2002;53:187-213

45. Stice E. Risk and maintenance factors for eating pathology: A metaanalytic review. Psychol Bull. 2002;128:825-848.

46. Kovacs M, Obrosky DS, Sherrill J. Developmental changes in the phenomenology of depression in girls compared to boys from childhood onward. J Affect Disord. 2003;74:33-48.

47. Davison KK, Birch LL. Child and parent characteristics as predictors of change in girls' body mass index. Int J Obes. 2001;25:1834-1842.

48. Birch LL, Fisher JO. Development of eating behaviors among children and adolescents. Pediatrics. 1998;101:539-549.

49. Abramovitz BA, Birch LL. Five-year-old girls' ideas about dieting are predicted by their mothers' dieting. J Am Diet Assoc. 2000; 100:1157-1163.

50. Cohen S, Williamson GM. Perceived stress in a probability sample of the United States. In: Spacapan S, Oskamp S, editors. The Social Psychology of Health. Newbury Park, CA: Sage; 1988.

51. Streigel-Moore RH. Etiology of binge eating: A developmental perspective. In: Fairburn CG, Wilson GT, editors. Binge Eating Nature, Assessment, and Treatment. New York, NY: Guilford; 1993.

52. Bracken B. Multidimensional Self Concept Scale. Austin, TX: Pro-Ed; 1992.

53. Strong KG, Huon GF. An evaluation of a structural model for studies of the initiation of dieting among adolescent girls. J Psychosom Res. 1998;44:315-326.

54. Montero A, Úbeda N, García A. Evaluación de los hábitos alimentarios de una población de estudiantes universitarios en relación con sus conocimientos nutricionales. Nutr Hosp. 2006;21:466-473.
International Journal of General Medicine

\section{Publish your work in this journal}

The International Journal of General Medicine is an international, peer-reviewed open-access journal that focuses on general and internal medicine, pathogenesis, epidemiology, diagnosis, monitoring and treatment protocols. The journal is characterized by the rapid reporting of reviews, original research and clinical studies across all disease areas.

\section{Dovepress}

A key focus is the elucidation of disease processes and management protocols resulting in improved outcomes for the patient.The manuscript management system is completely online and includes a very quick and fair peer-review system. Visit http://www.dovepress.com/ testimonials.php to read real quotes from published authors. 